\title{
Research Paper: Comparing Sexual Satisfaction and Function in Operated vs. Non-Operated Patients of Gender Identity Disorder
}

\author{
Elahe Asadpour ${ }^{1}$, Sare Behzadipuor ${ }^{1 *}$, Mohammad Zarenejad \\ 1. Department of Psychology, Shiraz Branch, Islamic Azad University, Shiraz, Iran. \\ 2. Legal Medicine Research Center, Legal Medicine Organization, Tehran, Iran
}

\begin{tabular}{|c|c|}
\hline $\begin{array}{l}\text { Use your device to scan } \\
\text { and read the article online }\end{array}$ & Citration Asadpour, E., Behzadipuor, S., \& Zarenejad, M. (2019). Comparing Sexual Satisfaction and Function in Operated \\
\hline 口itipin & $\begin{array}{l}\text { vs. Non-Operated Patients of Gender Identity Disorder. Journal of Practice in Clinical Psychology, 7(1), 71-78. http://dx.doi. } \\
\text { org/10.32598/jpcp.7.1.71 }\end{array}$ \\
\hline alytar & dol'http://dx.doi.org/10.32598/jpcp.7.1.71 \\
\hline
\end{tabular}

(i) (5)

Article info:

Received: 23 Jun 2018

Accepted: 14 Nov 2018

Available Online: 01 Jan 2019

Keywords:

Sexual function, Sexual satisfaction, Operated and non-operated patients, Gender Dysphoria

\section{ABSTRACT}

Objective: Gender Dysphoria is one of the most important psychiatric disorders whose complications include the problems occurring after sex reassignment surgery.

Methods: This study investigates sexual function and satisfaction in patients with Gender Dysphoria, both operated and non-operated patients, from 2011 to 2013. We used a crosssectional analysis, and by referring to the Legal Medicine Center in the province of Fars, 70 patients with Gender Dysphoria (including 35-operated male to female and 35 non-operated male to female) were selected using the non-probability sampling method. The study data were collected by sexual satisfaction standard questionnaires, sexual function index, and Beck scale for suicidal ideation were used. The results were analyzed using SPSS V. 22.

Results: According to the results, no significant difference was observed between the operated and non-operated groups in terms of sexual satisfaction. However, there was a significant difference in terms of sexual function among operated group compared to the non-operated group, at the significance level of 0.05 .

Conclusion: Based on our finding, the patients with sex reassignment surgery have found their identity, mental relaxation, and coordinated behavior with their genders. New sexual identity heals patients' relationship with society, presents individual in community with suitable social status and reasonable sexual function for achieving normal life.

\section{* Corresponding Author:}

Sare Behzadipuor, PhD.

Address: Department of Psychology, Shiraz Branch, Islamic Azad University, Shiraz, Iran.

Tel: +98 (917) 77138370

E-mail: sarebehzadi@gmail.com 


\section{Highlights}

- Gender Dysphoria (GD) is one of the most important psychiatric disorders whose complications continue even after sex reassignment surgery.

- No significant difference exists between the operated and non-operated groups for GD in terms of sexual satisfaction.

- However, there was a significant difference in terms of sexual function among these two groups.

- The GD patients after sex reassignment surgery found their identity, mental relaxation, and coordinated behavior with their genders.

\section{Plain Language Summary}

Gender Dysphoria (GD) or problem with own gender identity is one of the most important psychiatric disorders whose complications continue even after sex reassignment surgery. We investigated sexual function and satisfaction in patients with GD, in both operated and non-operated patients. According to the results, no significant difference was observed between the operated and non-operated groups in terms of sexual satisfaction. However, there was a significant difference in terms of sexual function among operated group compared to the non-operated group. Based on our finding, the patients with sex reassignment surgery have found their identity, enjoyed mental relaxation, and lived a coordinated behavior with their genders. New sexual identity restores patients' relationship with society, presents individual in community with suitable social status and reasonable sexual function for achieving normal life.

\section{Introduction}

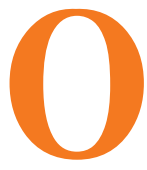

ne of the listed disorders in the diagnostic and statistical manual of mental disorders is the gender identity dysphoria disorder, which is presented as the difference between determined gender at birth and the mental impression of belonging to a particular gender (Vitelli \& Riccardi, 2011; Hedjazi, Zarenezhad, \& Hosseini, 2013). Several studies report an increased prevalence of Gender Dysphoria in subjects with sex disorders (De Vries, Doreleijers, Steensma, \& Cohen-Kettenis, 2011). The prevalence rates of Gender Dysphoria (GD) range between $0.005 \%$ and $0.014 \%$ in biological adult men and between $0.002 \%$ and $0.003 \%$ in biological women. The risk factors include natural, environmental, genetic, and physiological factors and cultural diagnostic issues.

With regard to sexual orientation, the most likely outcome of childhood GD is adult homosexuality or bisexuality. Clinicians (gender teams) serve these people because they usually suffer from child abuses and onefourth of the patients report childhood maltreatment (Bandini et al. 2011). This condition accompanies with severe clinical suffering in social and job performance or other functional areas or increases the risk of suffering such as distress or disability (Kaplan \& Sadock, 2015).
Most studies on transsexual patients focus on longterm psychological, surgical, and physical health, while just a few studies focus on their sexual life after genital (or gender or sex) reassignment surgery (Labus et al. 2011; Weyers et al. 2009). There are reports of sexual satisfaction after vaginoplasty in male to female patients, who were capable of achieving orgasm in 7080\% (De Cuypere et al. 2005). According to Life and Hubschman, a patient can be sexually satisfied following Sex Reassignment Surgery (SRS), despite inadequate sexual functioning (Lief \& Hubschman, 1993). Bartolucci et al. (2015) indicated that transsexual men generally have a good Quality of Life and experience satisfactory sexual function after SRS. De Vries et al. (2014) reported that after gender reassignment, in young adulthood, the GD got alleviated and psychological functioning steadily improved.

Johansson, Sundbom, Höjerback, \& Bodlun (2010) found that the majority of transsexual persons after SRS reported improved general functioning, while in another long-term follow-up cohort study, transsexual persons after sex reassignment surgery reported an increase in mortality and risk of suicide attempts compared to the controls (Dhejne et al. 2011). Mattila, Heinonen, Mäntymäki, Uusi-Mäkelä, \& Algars (2015) stated that GD was effectively alleviated by sex reassignment treatments. Quality of Life improved among the majority of 
the operated patients, and regrets were rare. Psychiatric symptoms at the initiation of the transition process, discrimination, negative attitudes, losses in relationships, and complications in somatic treatments may deteriorate the social integration and Quality of Life of the transgender people (De Vries et al., 2014; Mattila et al. 2015)

SRS is almost an irreversible process which causes fundamental changes in individual organs; therefore, it is gradually done to ensure that patients are aware of lifelong issues and complications of treatment and are psychologically ready to become a person of the opposite sex (De Cuypere, \& T'Sjoen, 2011).

Several researchers emphasize the importance of understanding the diversity of gender identities and expressions among transgender people, since it is an important precondition for specific health needs (Dhejne et al. 2011; Nimroozian, 2007), health risks (Nimroozian, 2007; Parola et al., 2010), and health outcome (De Vries et al., 2011). Unfortunately, GD often leads to discrimination against the affected person and can result in psychological complaints, such as anxiety and depression (Dhejne et al., 2011). While some transgender individuals can realize their gender identity without surgery, for many others, SRS is an essential and medically necessary step in the treatment of GD. Thus, as mentioned above, this study aims at comparing sexual satisfaction and function between operated and nonoperated patients with Gender Dysphoria.

\section{Methods}

This study investigated sexual function and satisfaction in patients with GD, operated and non-operated, between 2011 and 2013. This was a cross-sectional study. By referring to the Legal Medicine Center in the province of Fars, 70 patients with GD (35 operated male to female and 35 non-operated male to female ones) were selected by convenience sampling method. Complying with the legal and administrative regulations for interviewing people with GD and referring them to complete the judicial process, the study was conducted on the basis of Ethics codes of 7, 8, and 9 in the Department of Forensic Medicine of Fars Province, Iran.

The sample size was 70 (35 operated and 35 non-operated) GD patients. The study was done with the approval of Fars Legal Medicine Center with respect to the Helsinki Declaration for the preservation of human dignity, credit, and medical privacy policies. The patient's inclusion criteria were the definitive diagnosis of a psychiatric disorder, GD, by the commission and approval by Legal Medicine Center, with their complete information in their medical records (GD people who underwent the male to female SRS and those who were waiting for SRS). In addition, the subjects were 20 to 40 years old, and without a history of mental illness and hospitalization. Also, at least one year should have passed from SRS. The exclusion criteria included the lack of complete information in their records and unwillingness to cooperate, dropout, or death.

The results were analyzed in SPSS V. 22. In this study, demographic characteristics were analyzed by descriptive statistics such as mean, standard deviation, frequency, and frequency percentage. To investigate the relationship between age and education, with functioning and sexual satisfaction, the Spearman correlation coefficient was used. Finally, to compare dimensions of sexual satisfaction between two groups, multivariate analysis of variance was used.

Larson, Anderson, Holman, \& Niemann (1998) developed Larson's Sexual Satisfaction Questionnaire. This sexual satisfaction questionnaire has 25 questions and is scored from 1 to 5 . The items 4, 5, 6, 7, 8, 9, 11, 14, 15, $18,20,24,25$ are scored reversely. In response to each question, 5 options are included based on the Likert-type scale (never, rarely, sometimes, often, or always).

Each question is graded from 1 to 5 . The maximum score is 125 and the minimum is 25 points. Scores between 25 and 50 are considered lack of sexual satisfaction, 51 to 75 refers to least sexual satisfaction, 76 to 100 indicates moderate sexual satisfaction, and 100 to 125 as complete sexual satisfaction (Larson et al., 1998). The alpha was used as an estimate of reliability ( $\mathrm{a}=82 \%$ ) (Bahrami, Satarzadeh, Ranjbar Kochaksarani, $\&$ Ghochazadeh, 2007). The Cronbach $\alpha$ values for all positives and negative items were above 0.70 for the Persian version of Larson sexual satisfaction questionnaire (Bahrami, Sharif Nia, Soliemani, \& Haghdoost, 2016).

Rosen et al. (2000) developed the Sexual Function Index. It is used to determine the sexual function of the patients. According to Rozen et al. its convergent validity and test-retest reliability were reported as 0.88 for the total scale and 0.79 to 0.86 for its subscales (Rosen et al., 2000). The Cronbach $\alpha$ values in the Persian version were within the acceptable range of 0.72 to 0.90 for all domains indicating excellent internal consistency. The sexual function index is a multidimensional questionnaire with 19 items within six dimensions rated on a Likert-type scale from 0 to 5 or from 1 to 5 , which evalu- 
ate sexuality, eroticism, ejaculation, orgasm, sexual satisfaction, and painful intercourse.

The higher score represents better sexual function according to the effect of the areas; the maximum score for each field will be 6 and the total score will be 36 . The cut-off point for the total scale is 28 and the score higher than the cut-off point indicates good performance. The cut-off point for the whole scale and subscales is in the order of magnitude are 28 for the whole scale, 3 out of 3 for desire, 3 out of 4 for psychological stimulation, 3 out of 4 for moisture, 3 out of 4 for orgasms, 3 out of 8 for satisfaction, and 3 out of 8 for sexual pain (Rosen et al., 2000).

\section{Results}

The Mean \pm SD age of the study samples was $27.47 \pm 3.28$ years. About $48.57 \%$ had a high school diploma or lower education, $88.57 \%$ were single, $70 \%$ were unemployed, and $97.14 \%$ were residents of urban areas (Table 1 ). In addition, Table 1 lists the frequency and percentage of demographic characteristics of the study participants based on age, marital status, education, and occupation. The results of the Chi-square test on Table 1 indicate that the two groups matched for these variables.
Table 2 presents the mean and SD of descriptive statistics of the main variables of the research. The results showed a difference between the two groups in the dimensions of desire (Mean=4.45 for non-operated [male] and Mean=3.37 for operated), sexual stimulation (Mean=4.91 for non-operated [male] and Mean=4.00 for operated), vaginal moisture (Mean=3.83 for on-operated [male] and Mean=2.90 for operated), orgasm (Mean= 2.46 for non-operated [male] and Mean=2.80 for operated). Also, there is a difference between two groups in the case of pain during intercourse (Mean=5.00 for non-operated [male] and Mean=5.99 for operated). The Independent t-test was used to compare the sexual satisfaction of the two groups.

According to the level of significance $(\mathrm{P}=0.336)$, there is no difference between the sexual satisfaction of the non-operated group with the operated group (Table 3 ). Multivariate Analysis of Variance (MANVA) was used to compare the sexual function of the two groups. As shown in Table 4, according to the level of significance (0.005), there is a difference between the sexual function of the unworked and unproductive groups.

In order to understand the difference between the two dimensions of sexual function in the two groups

Table 1. The demographic characteristics of non-operated (male) and operated (female) study samples

\begin{tabular}{|c|c|c|c|c|c|c|c|}
\hline \multirow{2}{*}{ Variable } & \multirow{2}{*}{ Group } & \multicolumn{2}{|c|}{ Non-Operated (Male) } & \multirow{2}{*}{$\begin{array}{c}\text { Operated (Female) } \\
\text { No. }\end{array}$} & \multicolumn{3}{|c|}{ The Chi-Square Test } \\
\hline & & No. & $\%$ & & $\%$ & $\mathbf{X}^{2}$ & $\mathbf{P}$ \\
\hline \multirow{3}{*}{ Educational level } & Guidance school & 4 & 11.43 & 6 & 17.14 & \multirow{3}{*}{2.436} & \multirow{3}{*}{0.347} \\
\hline & Diploma & 12 & 34.29 & 12 & 34.29 & & \\
\hline & College degree & 19 & 54.28 & 17 & 48.57 & & \\
\hline \multirow{3}{*}{ Age, y } & $20-25$ & 9 & 25.71 & 12 & 34.29 & \multirow{3}{*}{3.134} & \multirow{3}{*}{0.299} \\
\hline & $26-30$ & 17 & 48.57 & 19 & 54.29 & & \\
\hline & 31 and above & 9 & 25.71 & 4 & 11.43 & & \\
\hline \multirow{2}{*}{ Marital status } & Single & 30 & 85.71 & 32 & 91.43 & \multirow{2}{*}{1.098} & \multirow{2}{*}{0.596} \\
\hline & Married & 5 & 14.29 & 3 & 8.57 & & \\
\hline \multirow{2}{*}{ Residential area } & Urban & 33 & 94.29 & 35 & 100 & \multirow{2}{*}{1.325} & \multirow{2}{*}{0.499} \\
\hline & Rural & 2 & 14.29 & 0 & 0 & & \\
\hline \multirow{3}{*}{ Occupation } & Unemployed & 21 & 60 & 11 & 40 & \multirow{3}{*}{5.689} & \multirow{3}{*}{0.102} \\
\hline & Student & 9 & 25.71 & 26 & 74.28 & & \\
\hline & Employed & 5 & 14.29 & 5 & 54.29 & & \\
\hline
\end{tabular}


Table 2. The dimensions of sexual function and sexual satisfaction of the subjects (operated and non-operated)

\begin{tabular}{|c|c|c|c|}
\hline Variable & Non-Operated (35 Males) & Operated (35 Females) & Total \\
\hline Dimension & & Mean $\pm S D$ & \\
\hline Sexual satisfaction & $5.22 \pm 2.33$ & $6.07 \pm 1.90$ & $5.64 \pm 2.10$ \\
\hline Sexual desire & $4.45 \pm 1.68$ & $3.37 \pm 1.44$ & $4.21 \pm 1.73$ \\
\hline Sexual arousal & $4.91 \pm 1.88$ & $4.00 \pm 1.68$ & $4.35 \pm 1.89$ \\
\hline Vaginal moisture or ejaculation & $3.83 \pm 1.57$ & $2.90 \pm 1.69$ & $3.37 \pm 1.99$ \\
\hline Orgasm & $2.46 \pm 1.01$ & $2.80 \pm 1.21$ & $2.63 \pm 1.33$ \\
\hline Pain & $5.00 \pm 2.23$ & $5.99 \pm 1.90$ & $5.64 \pm 2.10$ \\
\hline Sexual satisfaction & $3.49 \pm 1.76$ & $3.60 \pm 1.56$ & $3.54 \pm 1.34$ \\
\hline Sexual function & $24.14 \pm 5.56$ & $22.66 \pm 5.49$ & $22.73 \pm 7.83$ \\
\hline
\end{tabular}

Table 3. The comparison of the sexual performance of operated and non-operated patients with multivariate analysis of variance

\begin{tabular}{|c|c|c|c|c|}
\hline The Statistics & Value & $\mathbf{F}$ & df & $\mathbf{P}$ \\
\hline Pillai's trace & 0.232 & 6.60 & 68 & 0.005 \\
\hline
\end{tabular}

(Table 4). As can be seen in the Table 4, the findings show differences between two groups in the dimensions of desire (Mean=4.45 for non-operated [male] and Mean=3.37 for operated), sexual stimulation (Mean=4.91 for non-operated [male] and Mean=4.00 for operated), vaginal moisture (Mean=3.83 for nonoperated [male] and Mean=2.90 for operated), orgasm (Mean $=2.46$ for non-operated [male] and Mean=2.80 for operated), and pain (Mean=5.00 for non-operated [male] and Mean=5.99 for operated). However, there is no difference between the two groups with regard to sexual satisfaction (Mean= 3.49 for non-operated [male] and Mean=3.60 for operated).

\section{Discussion}

Our results indicate no significant differences between both groups in sexual satisfaction, but the patients with

Table 4. The comparison of dimensions of sexual function of operated and non-operated patients by 1-way analysis of variance analysis

\begin{tabular}{|c|c|c|c|c|c|}
\hline Variable & Non-Operated (35 Males) & Operated (35 Female) & \multirow{2}{*}{$\mathbf{F}$} & \multirow{2}{*}{ df } & \multirow{2}{*}{$\mathbf{P}$} \\
\hline Dimension & \multicolumn{2}{|c|}{ Mean \pm SD } & & & \\
\hline Sexual desire & $4.45 \pm 1.68$ & $3.37 \pm 1.44$ & 12.73 & 1 & 0.01 \\
\hline Sexual arousal & $4.91 \pm 1.88$ & $4.00 \pm 1.68$ & 11.93 & 1 & 0.01 \\
\hline Vaginal moisture or ejaculation & $3.83 \pm 1.57$ & $2.90 \pm 1.69$ & 9.94 & 1 & 0.01 \\
\hline Orgasm & $2.46 \pm 1.01$ & $2.80 \pm 1.21$ & 5.87 & 1 & 0.01 \\
\hline Pain & $5.00 \pm 2.23$ & $5.99 \pm 1.90$ & 9.98 & 1 & 0.01 \\
\hline Sexual satisfaction & $3.49 \pm 1.76$ & $3.60 \pm 1.56$ & 2.53 & 1 & 0.01 \\
\hline Sexual function & $24.14 \pm 5.56$ & $22.66 \pm 5.49$ & 22.73 & 1 & 0.46 \\
\hline
\end{tabular}


sex reassignment surgery reported significant function compared to non-operated patients. Our results on sexual satisfaction are consistent with the results of Jay, Louis, Sonja, James, \& Maeveet (2012). but are inconsistent with Nimroozian (2007) and Parola et al. (2010) studies. Based on the literature, operated and non-operated patients were involved in several problems such as hating their genitals, denying their biological sex, and belonging themselves to the opposite sex. Sexual problems ruin health and Quality of Life and general welfare of these patients. Lack of sexual information, sexual skills, expectation and unrealistic performance, inattention to satisfaction of sexual partner, maladaptive beliefs and attitudes, negative learning, negative emotions of sexuality, lack of intimacy, early damaging experiences in life, arousal and orgasm play an important role in life satisfaction (Jay et al. 2012; Nimroozian, 2007; Parola et al. 2010).

According to the research, gender reassignment operation has a positive effect on subjective well-being and sexual function (Klein \& Gorzalka, 2009; Gijs \& Brewaeys, 2007). Happich (2006) reported more than $90 \%$ satisfaction after SRS. Sexual function following surgery is a very important factor in satisfaction with gender reassignment. It primarily depends on the functionality of the vagina. Functional outcome satisfaction figures range from 56-84\% (Löwenberg, Lax, Neto, \& Krege, 2010; Imbimbo, Verze, Palmieri, 2009). In the authors' population, satisfaction with function was $72 \%$ ("very satisfied" and "satisfied") or $91.4 \%$ (including also "mostly satisfied").

According to Happich (2006), satisfaction with sexual experience is positively correlated with satisfaction with the surgery outcome. Other studies (Lawrence, 2003) have also found the surgical outcome to be one of the essential factors in postoperative satisfaction. In our study sample, general satisfaction with surgery was achieved in $87.4 \%$ of the patients. Regardless of surgical results, over half of the patients $(54.9 \%)$ were in the top third ("completely satisfied") and a further $38.2 \%$ in the middle third ("fairly satisfied") of the general life satisfaction scale (Hess, Neto, Panic, Rubben, \& Senf, 2014).

According to Sohn, Hatzinger, \& Wirsam (2013), 80\% subjective satisfaction rate can be expected following gender reassignment surgery. Löwenberg et al. (2010) reported $92 \%$ general satisfaction after SRS. Based on the follow-up sex reassignment interview, by Johansson et al (2010), almost all patients were satisfied with the sex reassignment; $86 \%$ were assessed by clinicians at follow-up as stable or improved in global functioning.
In another study examined Health, disability and Quality of Life among transgender people in Sweden-a webbased survey. Hess et al. (2014) studied satisfaction with male-to-female SRS. The very high rates of subjective satisfaction and surgical outcomes indicate that gender reassignment surgery is beneficial.

Perforation of the neovagina in male-to-female reassignment surgery and weak vagina after surgery (Shimamura et al (2015), tactile and erogenous sensitivity (Selvaggi et al., 2007), hormonal changes of testosterone and progesterone, neuroticism and structural differences in the brain are the factors that influence the quality of intercourse and decrease sexual satisfaction. According to Happich (2006), satisfaction with sexual experience is positively correlated with satisfaction with the outcome of surgery.

A study by Bartolucci et al. (2015) indicates that before genital SRS, about half of GD subjects perceived their sexual life as "poor/dissatisfied" or "very poor/very dissatisfied". Based on the available literature, transsexuals appear to have adequate sexual functioning and or high rates of sexual satisfaction following SRS (Klein \& Gorzalka, 2009). In addition, Garcia, Christopher, De Luca, Spilotros, \& Ralp. (2014) found that sexual function appears to be preserved and get better after surgery. However, a systematic review, which included 28 studies, proved the effects of sex reassignment surgery on mental health, psychological functioning, sexual functioning, and Quality of Life after surgery.

According to the literature, no similar research has been conducted on sexual activity in patients with Gender Dysphoria, so our study can pave the day for future studies on this topic. In this research, the level of participation and cooperation of people with gender identity disorder was weak due to poor people's trust in researchers, low motivation, and inadequate understanding of the research objectives. In addition, there was insufficient research in relation to sexual function and suicidal tendency. Many people were not willing to interview because of the cultural biases in our community and the gender issues in the questionnaire. Convenience sampling method and low sample size were other study limitations. Considering the importance of gender identity disorder and its effects on the lives of individuals, further research is recommended in these topics.

There are several problems that affect the sexual satisfaction in both treated and untreated people with GD but a significant difference was not observed between the two groups. The mean score of sexual desire, com- 
pared to untreated people, was also low. No similar studies have been found in the literature to compare sexual activity in people with Gender Dysphoria and this study could be a starting point for future research. Further studies and efforts are suggested to be done for gathering more knowledge about this disorder, its causes, and treatments, as well as preparing the community for the acceptance of these patients through mass media.

\section{Ethical Considerations}

\section{Compliance with ethical guidelines}

All ethical principles were considered in this article. The participants were informed about the purpose of the research and its implementation stages; they were also assured about the confidentiality of their information; Moreover, They were allowed to leave the study whenever they wish, and if desired, the results of the research would be available to them.

\section{Funding}

This research did not receive any specific grant from funding agencies in the public, commercial, or not-forprofit sectors.

\section{Authors contributions}

All authors contributed in preparing this article.

\section{Conflict of interest}

The authors declare no conflict of interest.

\section{Acknowledgements}

We sincerely thank to the Department of Forensic Medicine in Islamic Azad University, Shiraz Branch.

\section{References}

Anderson, K. M., Sharpe, M., \& Irvine, D. S. (2003). Distress and concerns in couples referred to a specialist infertility clinic. Journal of Psychosomatic Research, 54(4), 353-5. [DOI:10.1016/ S0022-3999(02)00398-7]

Bahrami, N., Satarzadeh, N., Ranjbar Kochaksarani, F., \& Ghochazadeh, M. (2007). [Investigation of sexual satisfaction and depression in fertile and infertile couples (Persian)]. Journal of Reproduction and Infertility, 8(1), 52-9.

Bahrami, N., Sharif Nia, H., Soliemani, M. A., \& Haghdoost, A. A. (2016). [Validity and reliability of the Persian version of Larson sexual Satisfaction Questionnaire in couples (Persian)]. Journal of Kerman University of Medical Sciences, 23(3), 344-356.

Bandini, E., Fisher, A. D., Ricca, V., Ristori, J., Meriggiola, M. C., Jannini, E. A., et al. (2011). Childhood maltreatment in subjects with male-to-female gender identity disorder. International Journal of Impotence Research, 23(6), 276-85. [DOI:10.1038/ ijir.2011.39] [PMID]

Bartolucci, C., Gómez-Gil, E., Salamero, M., Esteva, I., Guillamón, A., Zubiaurre, L., et al. (2015). Sexual Quality of Life in gender-dysphoric adults before genital sex reassignment surgery. The Journal of Sexual Medicine, 12(1), 180-8. [DOI:10.1111/ jsm.12758] [PMID]

De Cuypere, G., \& T'Sjoen, G. (2011). Quality of Life and sexual health after sex reassignment surgery in transsexual men. The Journal of Sexual Medicine, 8(12), 3379-88. [DOI:10.1111/j.17436109.2011.02348.x] [PMID]

De Cuypere, G., T'Sjoen, G., Beerten, R., Selvaggi, G., De Sutter, P., Hoebeke, P., et al. (2005). Sexual and physical health after sex reassignment surgery. Archives of Sexual Behavior, 34(6), 679-90. [DOI:10.1007/s10508-005-7926-5] [PMID]

De Vries, A. L., McGuire, J. K., Steensma, T. D., Wagenaar, E. C., Doreleijers, T. A., \& Cohen-Kettenis, P. T. (2014). Young adult psychological outcome after puberty suppression and gender reassignment. Pediatrics, 134(4), 696-704. [DOI:10.1542/ peds.2013-2958]

Dhejne, C., Lichtenstein, P., Boman, M., Johansson, A.L., Långström, N., \& Landén, M. (2011). Long-term follow-up of transsexual persons undergoing sex reassignment surgery: Cohort study in Sweden. PLoS One, 6(2), e16885. [DOI:10.1371/journal.pone.0016885]

Garcia, M. M., Christopher, N. A., De Luca, F., Spilotros, M., \& Ralph, D. J. (2014). Overall satisfaction, sexual function, and the durability of neophallus dimensions following staged female to male genital gender confirming surgery: The Institute of Urology, London U.K. experience. Translational Andrology and Urology, 3(2), 156-62. [PMID] [PMCID]

Gijs, L., \& Brewaeys, A. (2007). Surgical treatment of Gender Dysphoria in adults and adolescents: Recent developments, effectiveness, and challenges. Annual Review of Sex Research, 18(1), 178-224.

Happich, F. J. (2006). [Postoperative outcomes in transsexuality with special consideration of satisfaction: A follow-up (German)] [PhD dissertation]. Duisburg: University of Duisburg-Essen.

Hedjazi, A., Zarenezhad, M., \& Hosseini, M. (2013). Socio-demographic characteristics of transsexuals referred to the forensic medicine center in Southwest of Iran. North American Journal of Medical Sciences, 5(3), 224-7. [DOI:10.4103/19472714.109198] [PMID] [PMCID]

Hess, J., Neto R. R., Panic, L., Rübben, H., Senf, W. (2014). Satisfaction with male-to-female gender reassignment surgery: Results of a retrospective analysis. German Medical International Journal, 111(47), 795-801. [DOI:10.3238/arztebl.2014.0795]

Imbimbo, C., Verze, P., \& Palmieri, Al. (2009). A report from a single institute's 14-year experience in treatment of maleto-female transsexuals. The Journal of Sexual Medicine, 6(10), 2736-45. [DOI:10.1111/j.1743-6109.2009.01379.x] [PMID] 
McNeil, J., Bailey, L., Ellis, S., Morton, J., \& Regan, M. (2012). Trans mental health and emotional wellbeing study. Edinburgh: Equality Network.

Johansson, A., Sundbom, E., Höjerback, T., Bodlund, O. (2010). A five-year follow-up study of Swedish adults with gender identity disorder. Archives of Sexual Behavior, 39(6), 1429-37. [DOI:10.1007/s10508-009-9551-1]

Kaplan, H., \& Sadock, B. J. (2015). Comprehensive textbook of psychiatry. Philadelphia: Lippincott Williams \& Wilkins.

Klein, C., \& Gorzalka, B. B. (2009). Sexual functioning in transsexuals following hormone therapy and genital surgery: A review. The Journal of Sexual Medicine, 6(11), 2922-39. [DOI:10.1111/j.1743-6109.2009.01370.x]

Labus, L. D., Djordjevic, M. L., Stanojevic, D. S., Bizic, M. R., Stojanovic, B. Z., \& Cavic, T. M. (2011). Rectosigmoid vaginoplasty in patients with vaginal agenesis: Sexual and psychosocial outcomes. Sexual Health, 8(3), 427-30.

Larson, J. H., Anderson, S. M., Holman, T. B., Niemann, B. K. (1998). A longitudinal study of the effects of premarital communication, relationship stability and self-esteem on sexual satisfaction in the first year of marriage. Journal of Sex $\mathcal{E}$ Marital Therapy, 24(3), 195-206. [DOI:10.1080/00926239808404933]

Lawrence, A. A. (2003). Factors associated with satisfaction or regret following male-to-female sex reassignment surgery. Archives of Sexual Behavior, 32(4), 299-315. [DOI:10.1023/A:1024086814364] [PMID]

Lief, H. I., \& Hubschman, L. (1993). Orgasm in the postoperative transsexual. Archives of Sexual Behavior, 22(2), 145-55. [DOI:10.1007/BF01542363] [PMID]

Löwenberg, H., Lax, H., Neto, R. R, \& Krege, S. (2010). [Complications, subjective satisfaction and sexual experience by gender reassignment surgery in male-to-female transsexual (German)]. Zeitschrift für Sexualforschung (Journal of Sexology), 23(4), 328-47. [DOI:10.1055/s-0030-1262718]

Mattila, A., Heinonen, L., Mäntymäki, A., Uusi-Mäkelä, N., \& Algars, M. (2015). Effect of sex reassignment on mental wellbeing and Quality of Life. Duodecim, 131(4):379-81. [PMID]

Nimroozian, F. (2007). [Investigation of sexual satisfaction in male and female transsexual after sex reassignment surgery (Persian)] [MSc. thesis]. Tehran: Shahed university.

Parola, N., Bonierbale, M., Lemaire, A., Aghababian, V., Michel, A., \& Lançon, C. (2010). Study of Quality of Life for transsexuals after hormonal and surgical reassignment. Sexologies, 19(1), 24-8. [DOI:10.1016/j.sexol.2009.05.004]

Rosen, R., Brown, C., Heiman, J., Leiblum, S., Meston, C., Shabsigh, R., et al. (2000) The Female Sexual Function Index (FSFI) A multidimensional self-report instrument for the assessment of female sexual function. Journal of Sex E Marital Therapy, 26(2), 191-208. [DOI:10.1080/009262300278597] [PMID]

Rubin, S. O. (1995). A method of preserving the glans penis as aclitoris in sex conversion operations inmale transsexuals. Scandinavian Journal of Urology and Nephrology, 14(3), 215-7. [DOI:10.3109/00365598009179564]

Selvaggi, G., Monstrey, S., Ceulemans, P., T'sjoen, G., De Cuypere, G., \& Hoebeke, P. (2007). Genital sensitivity after sex reassignment surgery in transsexual patients. Annals of Plastic
Surgery, 58(4), 427-33. [DOI: 10.1097/01.sap.0000238428.91834 be] [PMID]

Shimamura, Y., Fujikawa, A., Kubota, K., Ishii, N., Fujita, Y., \& Ohta, K. (2015). Perforation of the neovagina in a male-to-female transsexual: A case report. Journal of Medical Case Reports, 9(1), 24. [DOI:10.1186/1752-1947-9-24]

Sohn, M. H., Hatzinger, M., \& Wirsam, K. (2013). [Operative genital adjustment in man-to-woman transsexuality: Are there any guidelines or standards (German)]. Hand Surgery, Microsurgery, Plastic Surgery, 45(4), 207-10. [DOI:10.1055/s-0033-1343427] [PMID]

Vitelli, R., \& Riccardi, E. (2010). Gender identity disorder and attachment theory: The influence of the patient's internal working models on psychotherapeutic engagement and objective. A study undertaken using the adult attachment interview. International Journal of Transgenderism, 12(4), 241-53. [DOI:10. 1080/15532739.2010.551485]

De Vries, A. L., Doreleijers, T. A., Steensma, T. D., \& CohenKettenis, P. T. (2011). Psychiatric comorbidity in gender dysphoric adolescents. Journal of Child Psychology and Psychiatry, 52(11), 1195-202. [DOI:10.1111/j.1469-7610.2011.02426.x] [PMID]

Weyers, S., Elaut, E., De Sutter, P., Gerris, J., T'sjoen, G., Heylens, G., et al. (2009). Long-term assessment of the physical, mental, and sexual health among transsexual women. The Journal of Sexual Medicine, 6(3), 752-60. 